\title{
3rd International Congress 'Restoration of (wheeled) mobility in SCI rehabilitation: State of the art III': its background
}
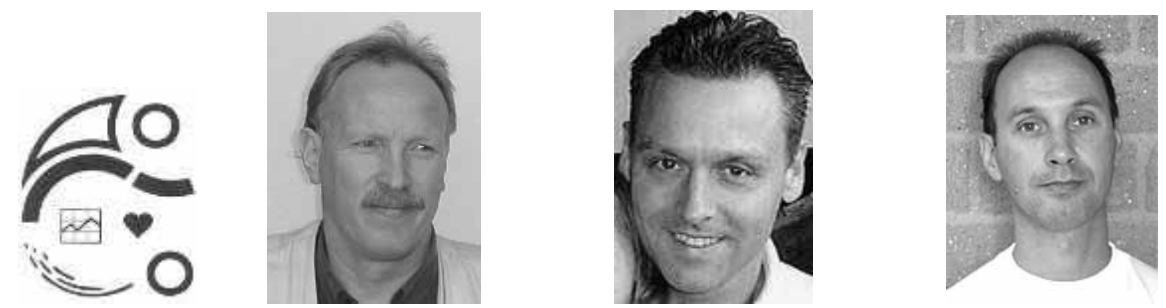

Lucas H.V. van der Woude ${ }^{\mathrm{a}, \mathrm{b}, *}$, Thomas W.J. Janssen ${ }^{\mathrm{a}, \mathrm{b}}$, and DirkJan Veeger ${ }^{\mathrm{a}, \mathrm{c}}$

${ }^{a}$ Institute for Fundamental and Clinical Movement Science, Faculty of Movement Sciences, Vrije Universiteit, Amsterdam, The Netherlands

' Rehabilitation Center "Amsterdam", Amsterdam, The Netherlands

${ }^{\mathrm{c}}$ Delft University of Technology, Delft, The Netherlands

\section{Introduction}

'Restoration of (wheeled) mobility in SCI rehabilitation' was the theme of a recent International Congress in Amsterdam, April 2004. 'Restoration of mobility in spinal cord injury' in its ultimate form would be to take away the cause of the mobility limitation, i.e. curing the spinal cord injury (SCI). Despite a large and basic research effort on neural regeneration, on spinal cord repair and on damage preventive - early intervention - strategies [30,52], there is no cure for spinal cord damage available today. In contrast to the strong financial research stimuli and the growing expectations on the success of neural repair as a cure for SCI, today's reality is that SCI is non-curable.

*Address for correspondence: Dr. L.H.V. van der Woude, Institute for Fundamental and Clinical Human Movement Science, Faculty of Human Movement Sciences, Vrije Universiteit, Van der Boechorststraat 9, 1081 BT Amsterdam, the Netherlands. E-mail: vdwoude@fbw.vu.nl.
SCI has long-term and far fetching consequences for daily functioning and freedom of mobility. As such there is an inevitable need for applied and basic research into SCI rehabilitation, into its goals, strategies, practices and where possible into new and innovative avenues of care improvement. This is what the 3rd International Congress 'Restoration of (wheeled) mobility in SCI rehabilitation: state of the art III' was aimed at. The following is a retrospective, both on the evolution of the research work of the research group at the Faculty of Human Movement Sciences in Amsterdam that formed the basis for the program themes, as well as a personal opinion on the research issues that are currently evolving from the rehabilitation field within the framework of restoration of mobility.

\section{Mobility}

Although mobility is an essential element in daily living, its importance is usually only then recognized 


\section{Health in Spinal Cord Injury}

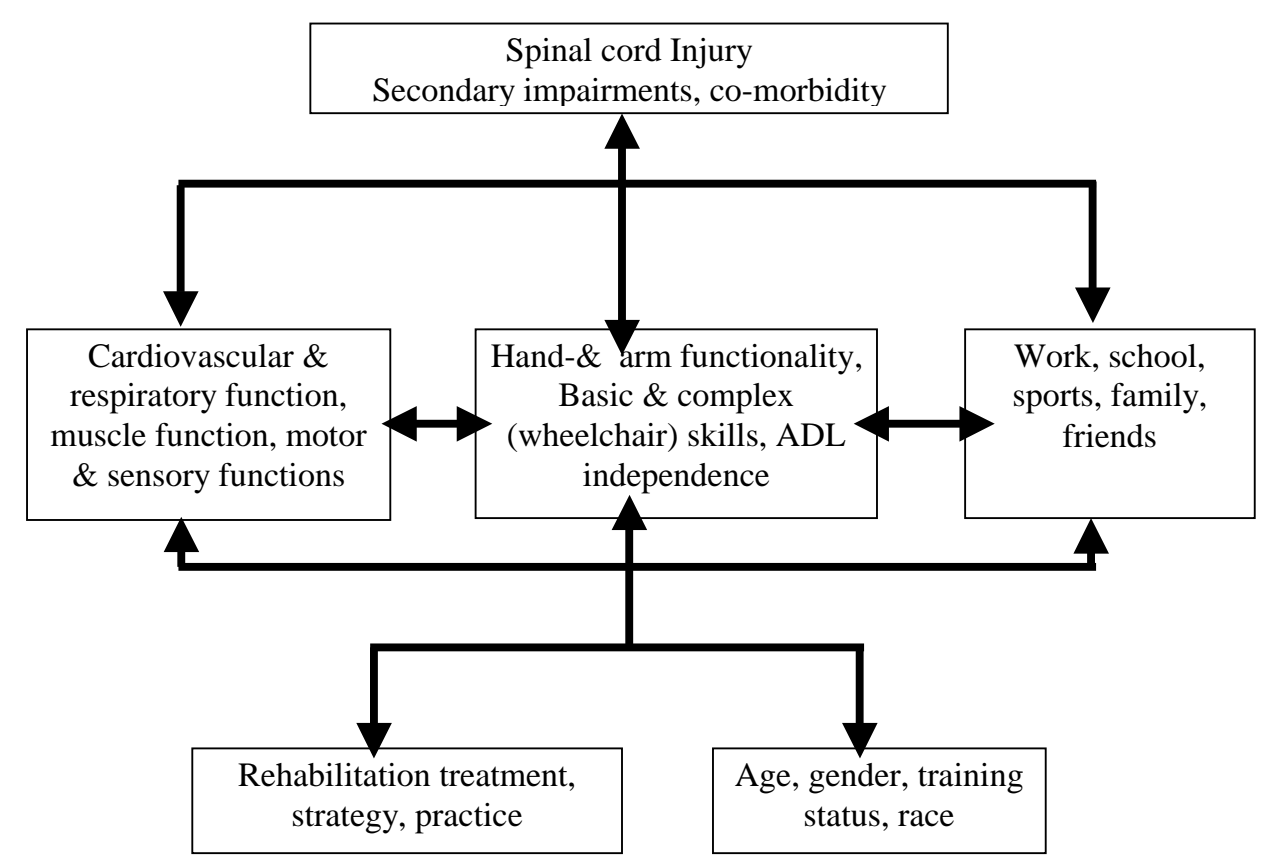

Fig. 1. ICF model, as applied to persons with SCI.

when it is for some reason (temporarily) limited. Mobility is a multi-layered concept. One can speak of joint mobility, but also of mobility as form of daily activity and even within the context of participation we use the term mobility. All three mentioned connotations of mobility substantiate main objectives of an integral rehabilitation process. As such, mobility can be positioned at each of the three domains of functioning within the International Classification of Functioning, Disability and Health (ICF) model [53]. This model is in many ways the starting point of research activities that are briefly reviewed below (Fig. 1).

Within the context of a chronic impairment, rehabilitation focuses on restoration of locomotion, ambulation or mobility in its widest sense. Continuing to be a mobile individual and having an optimal social and physical range of action, are key-objectives in SCI rehabilitation. In today's rehabilitation field, this goes beyond the mere restoration, compensation and (technologybased) adaptation of sensor-motor function, ADL functionality and independence. The issue of a physically active lifestyle during and after rehabilitation is becoming an issue on the rehabilitation research agenda $[8$, $13,15,40]$.

\section{The international congress}

The central theme of the 3rd International Congress was the restoration of mobility in SCI. The meeting was aimed at combining knowledge of exercise regimes, practice modes, learning and training protocols, rehabilitation strategies and front-edge assistive technology. Understanding of the underlying mechanisms and processes of adaptation and/or compensation of function and functioning (with or without the use of optimal assistive technology), is the core of rehabilitation research. The rehabilitation paradigm can be summarized as: 'to restore function and functionality, and to stimulate optimal activity and participation', a multicausal and multi-layered concept. As a theoretical framework, the ICF model was taken as a starting point for the program of the 3rd International Congress: mobility \& function, mobility \& activity and mobility \& participation, respectively. Issues that were addressed were as diverse as: hand-arm functionality, including orthotics and FES, treadmill walking, FES cycling, hand cycling, wheelchair propulsion, seating, physical activity and life style, mobility related secondary health problems, functional independence, quality of life, well-being, cultural and immigrant background, and participation. A sample of the excellent presenta- 
tions and research work performed can be found in this special issue.

The history of this 3rd International Congress dates back to the early 1990's, and explains the adjective '(wheeled)' in the title of the congress. In 1991 a first international scientific workshop on wheeled mobility was held at the Vrije Universiteit Amsterdam. This first workshop was fully dedicated to manual wheelchair propulsion [46]. The 2nd workshop was held again at the Vrije Universiteit in Amsterdam in 1998 and focused on (wheeled) mobility issues and questions in the area of spinal cord injury rehabilitation [48]. The 3rd International Congress can be viewed as a further widening of the scope from wheeled mobility to a more broader concept of mobility.

\section{From wheelchair research to a multidisciplinary program}

The scope of the 3rd International Congress has undergone a parallel development as the work on wheelchair propulsion since 1983 at the Faculty of $\mathrm{Hu}-$ man Movement Sciences in Amsterdam, the host for all three meetings. This research line started with a combined physiological and biomechanical approach into the optimization of wheelchair propulsion ability [47, 51]. Different performance influencing aspects, especially the ergonomics of the wheelchair-user interface, individual physical work capacity and various aspects of propulsion technique were studied, as well as aspects of vehicle mechanics. Recently, biophysical aspects of the learning process of hand rim wheelchair propulsion were incorporated [11] and hand cycling as a more efficient alternative mode of ambulation, became part of the research topics [10,27]. With the increasing understanding of wheelchair mobility, came a growing interest in the mechanical consequences of long term wheelchair use: the quest after the mechanisms and consequences of musculo-skeletal overuse in wheelchair use and ADL [4,10,27,49,50], especially in those with SCI. Apart from longitudinal research, in which epidemiological and experimental techniques are combined, this problem requires the use of detailed techniques for kinematics and kinetic $[1,41,51]$, as well as upper extremity modelling tools $[42,43,50]$.

\section{Assistive technology}

The interaction between assistive technology and the (disabled) human system is complex by definition and requires detailed research from a combined ergonomics and rehabilitation perspective. As an example, the long term use of assistive technology and its consequences on the musculoskeletal system has become an important issue in manual wheelchair research, where the continued imbalance between the task stresses, physical strain and overall mechanical and physiological work capacity lead to overuse injuries in the upper extremity [3]. Also, if assistive technology for mobility and the biological system do not function optimally, a debilitative cycle may start that can lead to an inactive lifestyle and consequently to a possible increased risk for secondary impairments, such as cardiovascular disease $[22,28]$. This stresses the important preventive role of an ergonomics approach within the field of rehabilitation and assistive technology.

Within the broader context of re-activation and restoration of mobility in SCI, bio-technical oriented SCI research recently evolved not only in the field of wheeled mobility, but also with respect to walking, i.e. body weight supported treadmill walking [12,21] and the use of gait-assisting robotics. Also, robotics in ADL and upper-extremity support $[18,36]$ and the upper extremity neuroprostheses for those with tetraplegia $[6,31,54]$, are examples of specific assistive technology that support restoration of function and functionality in SCI. Electrically stimulated (ES) cycling has been in the field for two decades. The therapeutic use of stationary recumbent ES bicycles in SCI has become common in some countries and has stimulated the development of technology for ES recumbent cycling in real life [2,14,17,39], allowing a more active lifestyle even in high lesion SCI. These devices will require an ergonomics oriented research input in order to reach an optimal long term functioning of the 'assistive technology-user' combination.

\section{6. (In)Activity}

After the importance of a physically active lifestyle was recognized for the general population in research $[5,19,20,39]$ and by influential (political) bodies such as the American College of Sports Medicine, ${ }^{1}$ Center for Disease Control ${ }^{2}$ and World Health Organization, ${ }^{3}$ it became even more evident, that (restoration of) an active lifestyle is probably even more important

\footnotetext{
${ }^{1}$ www.acsm.org.

${ }^{2}$ www.cdc.gov/nccdphp/dnpa/surveill.htm.

${ }^{3}$ www.who.int/hpr/physactiv/health.benefits.shtml.
} 
for those with a chronic disease or those involved in (clinical) rehabilitation $[8,13,15,40,45]$.

The focus onto the health-related mobility problem of a wheelchair confined life in individuals with SCI was recognized by Hjeltnes and Vokac [22] and later initiated in our research group by Janssen and Dallmeijer $[9,28,29]$. More and more the risks of a sedentary lifestyle have become apparent in international literature, as being one of the keystones to many chronic diseases, such as diabetes-II, syndrome X, or cardiovascular disease $[8,13,15,40,45]$. The prominent role of physical activity and lifestyle in the development or, better, prevention of long term health problems has become a specific issue that is clearly translated into the congress program theme and will have to be on the rehabilitation research agenda.

Apart from the common use of questionnaires for (in-)activity and lifestyle research, the use of small computer-based activity sensors has also entered activity monitoring in the field of rehabilitation [7,38,44]. Only few physical activity questionnaires are available for specific use in rehabilitation populations [45], while the more complex techniques require elaborate validation and reliability research for different subpopulations. They do allow, however, to observe the quantity as well as quality of ambulation in real life over a longer period of time, thus opening ways to stimulate and advise on activity and lifestyle, as well as quality of movement $[7,38,44]$.

\section{From outpatient to inpatient research}

For a Faculty of Human Movement Sciences at a Dutch university the transfer from outpatient to inpatient rehabilitation research was a major step that only became possible with the close collaboration with local rehabilitation centers, especially the Rehabilitation Center Amsterdam. ${ }^{4}$ SCI research within the Faculty of Human Movement Sciences and Institute for Fundamental and Clinical Human Movement Sciences over the years shifted away somewhat from the 'wheelchair core business' only, towards other forms of locomotion (i.e. hand cycling and electrical stimulation induced leg cycling) and more fundamental issues of cardiovascular adaptation [23-25], muscle physiology [16] and biomechanical upper extremity modelling [42,49,50]. Apart from changes in the biology due the initial paral-

\footnotetext{
${ }^{4}$ www.rcamsterdam.nl.
}

ysis, long term effects of chronic inactivity in SCI are studied, as well as the restoring effects of lower body exercise. The latter is often in the form of electrically stimulated leg cycling [26], and addresses both cardiovascular adaptation as well as muscle physiological aspects. The importance of more systematic research into underlying biological processes and mechanisms of adaptation and compensation of function and functioning in SCI is evidently expressed in this special issue, but also in today's literature.

\section{8. 'Restoration of mobility in SCI rehabilitation': A research program}

The 2004 congress has also its roots in the multidisciplinary research program "Functional strain, work capacity and restoration of mobility in the rehabilitation of persons with a spinal cord injury", ${ }^{5}$ which was initiated in 1998 and naturally evolved from the earlier wheelchair and SCI research. This program, in short 'Restoration of mobility in SCI rehabilitation', is a multi-center collaboration among five research groups, SCI units of eight rehabilitation centers in the Netherlands, and the Dutch-Flemish Society of Paraplegia ${ }^{6}$ (NVDG).

The multi-center program is presently formed by 12 complementary research projects, which cover various aspects of restoration of mobility in its broadest context. The benefits of such a long term multidisciplinary collaboration and the availability of larger numbers of subjects are evident. The development of such a large multidisciplinary program was only possible given the special infrastructure of Dutch rehabilitation health care and densely populated Dutch society, with the financial support of Rehabilitation Program of $\mathrm{ZONmw},{ }^{7}$ a national organization that promotes quality and innovation in the field of health research and health care.

This in turn facilitates the structured implementation of newly developed knowledge in the health care system and guarantees emerging health care issues a place on the research agenda. The backbone of the research program is formed by a prospective-cohort study. Little over 200 patients with SCI during and 1 year after initial rehabilitation performed a series of function and functional tests. The project measures each patient 4

\footnotetext{
${ }^{5}$ www.fbw.vu.nl/onderzoek//lijnA4.html.

${ }^{6}$ www.nvdg.org.

${ }^{7}$ ZONmw, Netherlands Organization for Health Research and Development, www.zonmw.nl.
} 


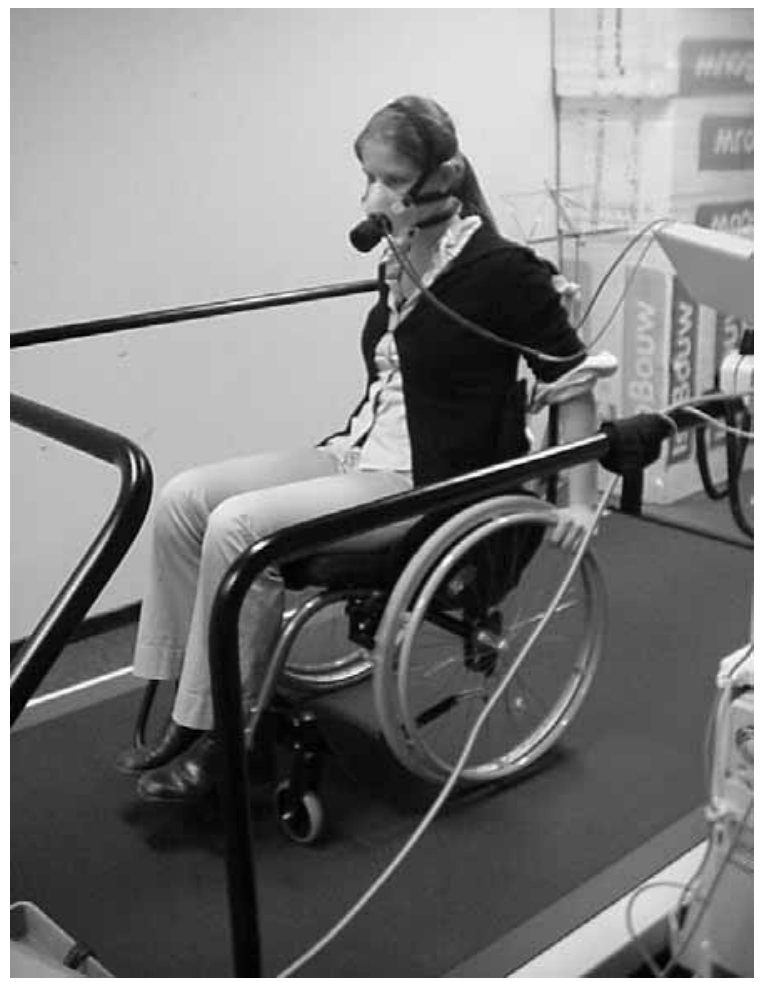

Fig. 2. A maximum wheelchair exercise test on a motor driven treadmill.

times with a standardized array of questionnaires and tests - among which arm-hand function tests in those with tetraplegia, a wheelchair skills test and maximum wheelchair exercise test on a motor driven treadmill (Fig. 2.), and a walking test in those with an incomplete lesion - and questionnaires covering many different aspects at each level of the ICF model. To understand the complexity of restoration of mobility in SCI, requires large subject numbers, combined experimental and epidemiological studies over time, as well as complex multilevel statistical techniques [10,31-35]. There is a strong need for such large group multidisciplinary prospective studies in rehabilitation for theory development and the evidence-base of treatment [37], from which future intervention studies as well as experimental studies must be derived.

\section{Concluding remarks}

Clearly, rehabilitation research has a need for multidisciplinary collaboration and exchange to tackle the (methodological) research questions and practical problems of today and to be prepared for the issues of tomorrow. An in-depth understanding of the origin and consequences of impaired function and functionality, the opportunities for treatment and prevention of secondary problems often requires multicenter and longitudinal collaboration, but also the multidisciplinary approach of experimental and intervention studies. Research into assistive technology for mobility must address the optimisation of the interaction the biological system in order to prevent long term health problems as a consequence of overuse. This and other issues require both specific and generic measurement tools and technology. International congress activities will contribute to these goals and processes.

\section{Acknowledgements}

The members of the congress organization team (Edmond D.L. Angenot, Kirsten E. Bijker, Stefan van Drongelen, Timon van der Scheer, Marjan Schot) and the scientific committee (Floris W.A. van Asbeck, Rita van den Berg, Michael Bergen, Hans Bussmann, Annet J. Dallmeijer, Sonja de Groot, Maria T.E. Hopman, Dirk J.M. van Kuppevelt, Anand V. Nene, Cees Pons, Marcel Post, Henk A.M. Seelen, Hans R. Slootman, Tebbe A.R. Sluis, Govert J. Snoek, Maarten J. IJzerman) are greatly acknowledged for their effort and input into the success of the 3rd International Congress.

\section{References}

[1] K.T. Asato, R.A. Cooper, R.N. Robertson and J.F. Ster, SMARTWheels: development and testing of a system for measuring manual wheelchair propulsion dynamics, IEEE Trans Biomed Eng 40 (1993), 1320-1324.

[2] R. Berkelmans and D.J. v. K. HJM, The development of a hybrid FES bike, Journal of Rehabilitation Research \& Development 41 (2004), S54.

[3] M.L. Boninger, R.A. Cooper, S.G. Fitzgerald, J. Lin, R. Cooper, B. Dicianno and B. Liu, Investigating neck pain in wheelchair users, Am J Phys Med Rehabil 82 (2003), 197-202.

[4] M.L. Boninger, B.G. Impink, R.A. Cooper and A.M. Koontz, Relation between median and ulnar nerve function and wrist kinematics during wheelchair propulsion, Arch Phys Med Rehabil 85 (2004), 1141-1145.

[5] D.R. Brown, R.R. Pate, M. Pratt, F. Wheeler, D. Buchner, B. Ainsworth and C. Macera, Physical activity and public health: training courses for researchers and practitioners, $P u b$ lic Health Rep 116 (2001), 197-202.

[6] A.M. Bryden, K.S. Wuolle, P.K. Murray and P.H. Peckham, Perceived outcomes and utilization of upper extremity surgical reconstruction in individuals with tetraplegia at model spinal cord injury systems, Spinal Cord 42 (2004), 169-176. 
[7] H.B. Bussmann, P.J. Reuvekamp, P.H. Veltink, W.L. Martens and H.J. Stam, Validity and reliability of measurements obtained with an "activity monitor" in people with and without a transtibial amputation, Phys Ther 78 (1998), 989-998.

[8] R.A. Cooper, L.A. Quatrano, P.W. Axelson, W. Harlan, M. Stineman, B. Franklin, J.S. Krause, J. Bach, H. Chambers, E.Y. Chao, M. Alexander and P. Painter, Research on physical activity and health among people with disabilities: a consensus statement, J Rehabil Res Dev 36 (1999), 142-154.

[9] A.J. Dallmeijer, M.T. Hopman and L.H. van der Woude, Lipid, lipoprotein, and apolipoprotein profiles in active and sedentary men with tetraplegia, Arch Phys Med Rehabil 78 (1997), 11731176.

[10] A.J. Dallmeijer, L. Ottjes, E. de Waardt and L.H. van der Woude, A physiological comparison of synchronous and asynchronous hand cycling, Int J Sports Med 25 (2004), 622-626.

[11] S. de Groot, H.E. Veeger, A.P. Hollander and L.H. van der Woude, Influence of task complexity on mechanical efficiency and propulsion technique during learning of hand rim wheelchair propulsion, Med Eng Phys 27 (2005), 41-49.

[12] V. Dietz and G. Colombo, Recovery from spinal cord injuryunderlying mechanisms and efficacy of rehabilitation, Acta Neurochir Suppl 89 (2004), 95-100.

[13] J.L. Durstine and G.E. Moore, ACSM's Exercise management for persons with chronic diseases and disabilities, Chapaign: Human Kintecs, ACSM, 2003.

[14] C. Formusek and G. Davis, Technical design of a novel isokinetic FES exercise bicyle for spinal cord injured individuals, J Rehabil Res Dev 41 (2004), S53.

[15] W. Frontera, Exercise in Rehabilitation Medicine, Champaign: Human Kinetics, 1999.

[16] H.L. Gerrits, M.T. Hopman, C. Offringa, B.G. Engelen, A.J. Sargeant, D.A. Jones and A. Haan, Variability in fibre properties in paralysed human quadriceps muscles and effects of training, Pflugers Arch 445 (2003), 734-740.

[17] M. Gfohler, M. Loicht and P. Lugner, Exercise tricycle for paraplegics, Med Biol Eng Comput 36 (1998), 118-121.

[18] J. Hammel, K. Hall, D. Lees, L. Leifer, M. Van der Loos, I. Perkash and R. Crigler, Clinical evaluation of a desktop robotic assistant, J Rehabil Res Dev 26 (1989), 1-16.

[19] W.L. Haskell and J.B. Wolffe, Memorial Lecture. Health consequences of physical activity: understanding and challenges regarding dose-response, Med Sci Sports Exerc 26 (1994), 649-660.

[20] W.L. Haskell, Physical activity, sport, and health: toward the next century, Res Q Exerc Sport 67 (1996), S37-S47.

[21] R. Herman, J. He, S. D'Luzansky, W. Willis and S. Dilli, Spinal cord stimulation facilitates functional walking in a chronic, incomplete spinal cord injured, Spinal Cord 40 (2002), 65-68.

[22] N. Hjeltnes and Z. Vokac, Circulatory strain in everyday life of paraplegics, Scand J Rehabil Med 11 (1979), 67-73.

[23] M.T. Hopman, J.T. Groothuis, M. Flendrie, K.H. Gerrits and S. Houtman, Increased vascular resistance in paralyzed legs after spinal cord injury is reversible by training, J Appl Physiol 93 (2002), 1966-1972.

[24] M.T. Hopman, S. Houtman, J.T. Groothuis and H.T. Folgering, The effect of varied fractional inspired oxygen on arm exercise performance in spinal cord injury and able-bodied persons, Arch Phys Med Rehabil 85 (2004), 319-323.

[25] M.T. Hopman, M. Monroe, C. Dueck, W.T. Phillips and J.S. Skinner, Blood redistribution and circulatory responses to submaximal arm exercise in persons with spinal cord injury, Scand J Rehabil Med 30 (1998), 167-174.
[26] T.W. Janssen, M. Bakker, A. Wyngaert, K. Gerrits and S.D. Haan, Effects of stimulation pattern on electrical stimulationinduced leg cycling performance, Journal of Rehabilitation Research \& Development 41 (2004), 787-796.

[27] T.W. Janssen, A.J. Dallmeijer and L.H. van der Woude, Physical capacity and race performance of handcycle users, $J$ Rehabil Res Dev 38 (2001), 33-40.

[28] T.W. Janssen, C.A. van Oers, E.P. Rozendaal, E.M. Willemsen, A.P. Hollander and L.H. van der Woude, Changes in physical strain and physical capacity in men with spinal cord injuries, Medicine and Science in Sports and Exercise 28 (1996), 551559.

[29] T.W. Janssen, C.A. van Oers, G.J. van Kamp, B.J. TenVoorde, L.H. van der Woude and A.P. Hollander, Coronary heart disease risk indicators, aerobic power, and physical activity in men with spinal cord injuries, Arch Phys Med Rehabil 78 (1997), 697-705.

[30] JRRD, 10th International Symposium on Neural regeneration, Journal of Rehabilitation Research and Development 40 (2003).

[31] K.L. Kilgore, P.H. Peckham, M.W. Keith, F.W. Montague, R.L. Hart, M.M. Gazdik, A.M. Bryden, S.A. Snyder and T.G. Stage, Durability of implanted electrodes and leads in an upper-limb neuroprosthesis, J Rehabil Res Dev 40 (2003), $457-468$.

[32] O.J. Kilkens, M. Post, H.A. M. Seelen, A. Dallmeijer and L. Van Der Woude, Longitudinal development of manual wheelchair skill performance during inpatient rehabilitation of persons with a spinal cord injury: associations with subject characteristics, lesion charcteristics, secondsary complications and co-morbidity, Arch Phys Med \& Rehabil, accepted, 2005.

[33] O.J. Kilkens, A.J. Dallmeijer, L.P. De Witte, L.H. Van Der Woude and M.W. Post, The Wheelchair Circuit: Construct validity and responsiveness of a test to assess manual wheelchair mobility in persons with spinal cord injury, Arch Phys Med Rehabil 85 (2004), 424-431.

[34] O.J. Kilkens, M.W. Post, A.J. Dallmeijer, H.A. Seelen and L.H. van der Woude, Wheelchair skills tests: a systematic review, Clin Rehabil 17 (2003), 418-430.

[35] O.J. Kilkens, M.W. Post, L.H. van der Woude, A.J. Dallmeijer and W.J. van den Heuvel, The wheelchair circuit: reliability of a test to assess mobility in persons with spinal cord injuries, Arch Phys Med Rehabil 83 (2002), 1783-1788.

[36] P.S. Lum, C.G. Burgar, P.C. Shor, M. Majmundar and M. Van der Loos, Robot-assisted movement training compared with conventional therapy techniques for the rehabilitation of upper-limb motor function after stroke, Arch Phys Med Rehabil 83 (2002), 952-959.

[37] R.J. Marino, J.F. Ditunno, Jr., W.H. Donovan and F. Maynard, Jr., Neurologic recovery after traumatic spinal cord injury: data from the Model Spinal Cord Injury Systems, Arch Phys Med Rehabil 80 (1999), 1391-1396.

[38] A. Nunn, J. McLeod, I. Brown, A. Ting, P. Early and R. Hawkins, Monitoring patients with SCI during activity using a datalogger, Journal of Rehabilitation Research \& Development 41:47 (2004).

[39] W. Reichenfelser, M. Gfoehler and T. Angeli, Design of a testand-training tricyle for paraplegics, Journal of Rehabilitation Research \& Development 41 (2004), S28-S29.

[40] J.H. Rimmer and D. Braddock, Health promotion for people with physical, cognitive and sensory disabilities: an emerging national priority, Am J Health Promot 16 (2002), 220-224. 
[41] R.N. Robertson, M.L. Boninger, R.A. Cooper and S.D. Shimada, Pushrim forces and joint kinetics during wheelchair propulsion, Arch Phys Med Rehabil 77 (1996), 856-864.

[42] L.A. Rozendaal and D.E. Veeger, Force direction in manual wheel chair propulsion: balance between effect and cost, Clin Biomech (Bristol, Avon) 15(Suppl 1) (2000), S39-S41.

[43] S.D. Shimada, R.A. Cooper, M.L. Boninger, A.M. Koontz and T.A. Corfman, Comparison of three different models to represent the wrist during wheelchair propulsion, IEEE Trans Neural Syst Rehabil Eng 9 (2001), 274-282.

[44] D.G. Smith, E. Domholdt, K.L. Coleman, M.A. Del Aguila and D.A. Boone, Ambulatory activity in men with diabetes: Relationship between self-reported and real-world performance-based measures, J Rehabil Res Dev 41 (2004), 571-580.

[45] H.P. Van der Ploeg, A.J. van der Beek, L.H. van der Woude and W. van Mechelen, Physical activity for people with a disability: a conceptual model, Sports Med 34 (2004), 639-649.

[46] L.H. Van der Woude, P. Meijs, B. van der Grinten and Y. de Boer, Ergonomics of Manual Wheelchair Propulsion, State of the Art, Amsterdam: IOS press, 1993, p. 366.

[47] L.H. Van der Woude, G. de Groot, A.P. Hollander, G.J. van Ingen Schenau and R.H. Rozendal, Wheelchair ergonomics and physiological testing of prototypes, Ergonomics 29 (1986), 1561-1573.

[48] L.H. Van der Woude, V. v. d., M. Hopman and C.H. Van Kemenade, Biomedical Aspects of Manual Wheelchair Propulsion: State of the Art II, Amsterdam: IOS press, 1999, 392.

[49] S. Van Drongelen, L. van der Woude, T. Janssen, E. Angenot and $\mathrm{H}$. Veeger, Mechanical loading during wheelchair related $A D L$, Arch Phys Med Rehabil, accepted.

[50] H.E. Veeger, L.A. Rozendaal and F.C. van der Helm, Load on the shoulder in low intensity wheelchair propulsion, Clin Biomech (Bristol, Avon) 17 (2002), 211-218.

[51] H.E. Veeger, L.H. van der Woude and R.H. Rozendal, A computerized wheelchair ergometer. Results of a comparison study, Scand J Rehabil Med 24 (1992), 17-23.

[52] J. Vehaagen, Cell and gene therapy strategies to promote repair of the injured rat spinal cord, J Rehabil Res and Develop $\mathbf{4 1}$ (2004), 15-16.

[53] WHO, International Classification of Functioning, Disability and Health, Geneva: World Health Organisation, 2001.

[54] K.S. Wuolle, A.M. Bryden, P.H. Peckham, P.K. Murray and M. Keith, Satisfaction with upper-extremity surgery in individuals with tetraplegia, Arch Phys Med Rehabil 84 (2003), 11451149 . 